\title{
Effect of Type of Sugar and Dough Relaxation Time on the Shape Characteristics of Biscuits
}

\author{
ANUJ NIROULA*, AASTHAPOKHAREL, AND JYOTI ACHARYA
}

Department of Food Technology, Nagarik College, Tribhuvan University, Nepal.

\begin{abstract}
This study was aimed to evaluate the effect of type of sugars namely dextrose, sucrose, sucrose-invert syrup mix, invert syrup and honey, and dough relaxation time of 15, 40, and $65 \mathrm{~min}$. on the shape characteristics viz. width, thickness, spread ratio, and an expansion ratio of biscuits. The type of sugars significantly affected $(p<0.05)$ all shape characteristics, while the dough relaxation only affected those of crystal sugars (sucrose and dextrose). High dough relaxation time enhanced the width of sucrose biscuits without significantly affecting $(p>0.05)$ their thickness. In contrast, the thickness of dextrose biscuits decreased with increasing relaxation time. Liquid sugars (invert syrup and honey) enhanced the width of biscuits; the former enhancing the thickness as well. The study also demonstrated that a high spread ratio may also be associated witha low expansion ratio. Hence, both the spread ratio and expansion ratio must be considered when discussing the shape characteristics of biscuits with different ingredients.
\end{abstract}

Keywords: Biscuit, dough relaxation, expansion ratio, physical characteristics, spread ratio

\section{Introduction}

Biscuits are a traditional type of flour (usually wheat) confectionery that has low water content $(<5 \%)$, the high energy density at low cost, good sensorial quality, and long shelf-life when protected from moisture and oxygen. Through development and innovation for several centuries biscuits can nowadays be consumed as staple foods, snacks, luxury gifts, dietary products, infant foods, dog and cat foods, etc., and with additions of chocolate and cream, etc., they borderline with confectionery (Manley, 2011a). The shape characteristics viz. width, thickness, spread ratio, and expansion ratio, of biscuits has a direct relation to product uniformity, quality, and consumer acceptance (Chauhan et al., 2016; Sai Manohar \& Haridas Rao, 2002) and influence the processing and/or packaging efficiency. Therefore, the shape characteristics of biscuits are crucial and should be kept under control.

The post-baking shape characteristics of biscuits are influenced by several factors like recipe formulation, flour quality, types of sugar, mixing type, time, and baking profile (Manley, 1998; Manley et al., 2011). Sugar is the most important ingredient contributing to the shape of biscuits. Sugar effects on the lateral expansion and machining properties of dough by its extent of dissolution depending on the particle size and solubility (Pareyt et al., 2009; van der Sman \& Renzetti, 2018; Zoulias et al., 2000). From a functional viewpoint, sugar restricts the development of gluten by competing for water which otherwise would have been absorbed by the gluten (Maache-Rezzoug et al., 1998; Manley, 2011b). Development of gluten contributes to the vertical expansion of cookies (Handa et al., 2012), and a very strong network results in snap-back of a dough piece and irregular surface or shape (Kweon et al., 2009; van der Sman \& Renzetti, 2018). The gluten network and strength of dough have also been correlated to the relaxation behavior of dough (Safari-ardi \& Phan-thien, 1998). At constant viscosity, the relaxation time of about $1000 \mathrm{sec}$ is ideal for hard wheat flour dough baking (Bagley et al., 1988). But with an increase in relaxation of dough, the elastic and loss *Corresponding author, e-mail address : an.niroula@gmail.com modulus of dough are usually reduced which aids in piece formation, prevents shrinkage, and yield laterally expanded products with a small vertical expansion (Maache-Rezzoug et al., 1998). The free moisture, total solvent volume and viscosity are other important parameters that can alter the dough property during relaxation and affect the shape of biscuits.

Besides types of sugars and dough relaxation time, the dimensions of biscuits are significantly affected by various other parameters, like flour properties, type of mixing, time of mixing, dimensions of dough piece, baking temperature profile, etc. Considerable information is available on the influence of quantity and particle size of sucrose on the spread and overall quality of biscuits and cookies. However, different types of sugars when induced to dough can impart variable shape in biscuits depending on their water holding capacity and solubility that influence the viscosity, gluten formation, and gelatinization temperature of the dough. Further, the optimum relaxation time of dough to have optimum spread may also change with the type of sugar used during the dough making process. Therefore, keeping all other factors constant, this work was aimed to study the effects of different types of sugar and dough relaxation time on the shape characteristics of biscuits.

\section{Materials and methods \\ Raw materials}

Wheat (Triticum aestivum var. Gautam) was milled to refined wheat flour in Munal Food Products, Gaindakot, Nepal. Other ingredients used in the biscuits, like sugar, table salt, baking soda; butter, and honey were collected from Bhat-Bhateni supermarket of Chitwan. Indu Shankar Sugar Mill manufactured sugar, Salt Trading Corporation Limited packed table salt, Hetauda Dairy Industry (Newarpani) manufactured butter, Weikfield Foods Pvt. Ltd. (India) manufactured baking soda, Patanjali Ayurveda Kendra Pvt. Ltd.packed honey and Amrut International (India) manufactured food grade dextrose granules were used. 


\section{Preparation of biscuits}

Short-dough were prepared with refined wheat flour (100 parts), sugars (44 parts), butter (24) parts), salt (0.85 parts), and sodium bicarbonate (1.7 parts) in dry weight basis. Total water in the dough was 31 parts, obtained by reducing the amount of water present in flour $(12.15 \%)$, butter $(20 \%)$, invert syrup (IS) $(20 \%)$ and honey (18\%). Crystal sugars: sucrose and dextrose, and liquid sugars: IS and honey, and sucrose-invertsyrup (1:1 in dry basis) mix (S-IS) were used to prepare biscuit dough.

Ingredients other than flour were creamed for $2 \mathrm{~min}$ and subjected to mixing for $3 \mathrm{~min}$ after the addition of flour, to reduce the potential gluten formation in dough compared to all in one mixing (Sai Manohar \& Haridas Rao, 1999). The dough was allowed to relax for 15, 40, and $65 \mathrm{~min}$. The dough was turned $90^{\circ}$ after each sheeting to avoid gluten development and the subsequent deformation (Laguna et al., 2013). Dough sheets were maintained to $3.5 \mathrm{~mm}$ thickness and cut to $37 \mathrm{~mm}$ circular diameter. Baking was carried at $180 / 200^{\circ} \mathrm{C}$ top/bottom heat for $15 \mathrm{~min}$ and cooled in desiccators for 3 hours at ambient temperaturebefore evaluation.

\section{Evaluation of physical dimensions}

Physical attributes considered during the study were diameter, stack height, spread ratio, and expansion ratio. Five biscuits were randomly chosen and stacked vertically to measure its average thickness. The biscuits were turned $90^{\circ}$ and the average width was determined with digital vernier caliper (Lutron, Model: DC-515). Spread ratio was calculated as the ratio of diameter to thickness of each biscuit and expansion ratio was calculated as the ratio of the final volume of biscuit to the initial volume of dough.

$$
\text { Spread ratio }=\frac{\text { Diameter } * \text { No. of biscuit in a stock }}{\text { Stack height }}
$$

\section{Statistical evaluations}

Preparation and evaluation of biscuits werecarried out in 2 blocks and evaluations were 8 replicates per sample in each block.The data obtained were statistically analyzed using one-way analysis of variance (ANOVA) among samples at $5 \%$ level of significance (i.e. $\mathrm{p}<0.05$ ). Tukey test was used as a post-hoc test and all these analyses were performed using JMP Pro 14.

\section{Results and Discussion \\ Effect on the width of biscuits}

In this study, the widths of biscuits were significantly affected $(\mathrm{p}<0.05)$ by the type of sugar, and dough relaxation time (Table 1). The highest width was obtained in biscuits prepared with invert syrup despite relaxation time. When the dough was relaxed for $15 \mathrm{~min}$ only, invert syrup had significantly higher $(\mathrm{p}<0.05)$ width followed by honey. Both of these are aqueous reducing sugars and were significantly higher than biscuits prepared with S-IS and the crystalline sugars i.e. sucrose and dextrose.The decreasing order of the width of biscuits with liquid sugars, liquid-crystal mix, and crystals was possibly due to the volume of total solvent in the dough (Kweon et al., 2009; van der Sman \& Renzetti, 2018). Sai Manohar \& Haridas Rao(1997) also reported that biscuits prepared with higher reducing sugars present in the soluble aqueous phase (i.e. syrup) hadhigher width compared to those prepared with non-reducing sugar (i.e. sucrose) and reducing sugars in the crystalline state.

The width of biscuits prepared from invert syrup and honey were unaffected $(p>0.05)$ by dough relaxation time. This may be due to the presence of all sugars in them in the dissolved state so that no change in the total volume of solvent in dough occurred during enhanced relaxation time. The width of biscuits significantly increased $(p<0.05)$ with the increase in dough relaxation time to $40 \mathrm{~min}$ for biscuits prepared with sucrose and S-IS. This increase in width was possibly associated with the dissolution of sucrose in the dough during relaxation. The sugars were not fully dissolved in the formulation of Abboud \& Hoseney (1984) but in other formulation investigated by Chevallier, Colonna, \& Bule(2000), sugars were fully solubilized. Hence, the extent of dissolution of sugars in the dough may depend on theproportions of flour, sugar, and water, the type of flour, and solubility of sugars (van der Sman \& Renzetti, 2018). The dissolution of sucrose increases the volume of the total solvent in the dough, which reduces the viscosity of dough during baking to increase the width of biscuits (Kweon et al., 2009; van der Sman \& Renzetti, 2018). The dissolution of sugars has also been reported to have an important role in the extent of lateral expansion of biscuits by Handa et al. (2012). Further increase in relaxation time had no statistical difference $(\mathrm{p}>0.05)$ in both cases.

Table 1

Width of biscuits prepared with different types of sugars and dough relaxation time*

\begin{tabular}{ccccccc}
\hline \multirow{2}{*}{$\begin{array}{c}\text { Relaxation } \\
\text { time (min) }\end{array}$} & $\begin{array}{c}\text { Initial width } \\
(\mathbf{m m})\end{array}$ & \multicolumn{4}{c}{ Final width (mm) } \\
\cline { 3 - 7 } & & Sucrose & Dextrose & S-IS & IS & Honey \\
\hline 15 & $37^{\mathrm{e}}$ & $39.83 \pm 0.79^{\mathrm{Bd}}$ & $39.34 \pm 0.78^{\mathrm{Acd}}$ & $40.73 \pm 0.54^{\mathrm{Bc}}$ & $45.03 \pm 0.43^{\mathrm{Aa}}$ & $42.58 \pm 0.40^{\mathrm{Ab}}$ \\
\hline 40 & $37^{\mathrm{c}}$ & $42.50 \pm 0.97^{\mathrm{Ab}}$ & $37.36 \pm 0.57^{\mathrm{Bc}}$ & $45.53 \pm 0.74^{\mathrm{Aa}}$ & $44.96 \pm 0.71^{\mathrm{Aa}}$ & $42.21 \pm 0.80^{\mathrm{Ab}}$ \\
\hline 65 & $37^{\mathrm{c}}$ & $42.03 \pm 0.79^{\mathrm{Ab}}$ & $35.46 \pm 0.59^{\mathrm{Cd}}$ & $44.85 \pm 0.80^{\mathrm{Aa}}$ & $45.39 \pm 0.86^{\mathrm{Aa}}$ & $42.33 \pm 0.79^{\mathrm{Ab}}$
\end{tabular}

* All means and SD are calculated from 16 stacks (each with 5 pieces) collected in 2 blocks and 8 replicates per block. IS: invert syrup, S-IS: sucrose-invert syrup (1:1 in dry basis) mix. Different capital letters superscript in a column and small letters superscript in a row indicate significant difference among sample means at $\mathrm{p}<0.05$ such that $A>B>C$ and $a>b>c>d>e$. 
Hence, the optimum relaxation time for biscuit dough prepared with sugars and S-IS was $40 \mathrm{~min}$.However, the $40 \mathrm{~min}$ and further significantly decreased $(\mathrm{p}<0.05)$ when the relaxation time was elongated to $65 \mathrm{~min}$. This was possibly due to the elastic nature of dough prepared with dextrose due to the formation of the extensive gluten network, which results in the snap-back of the sheeted and cut dough piece with out of round shape. Reduction in the width with the increase in relaxation time may be due to the strengthening of gluten structure that resulted in a higher snap back. Snap-back after sheeting and cutting of dough piece with crystalline glucose and xylose has been reported to occur and result in was also reported by Kweon et al. (2009).

\section{Effect on the thickness of biscuits}

The hydration and development of gluten contribute to the expansion in height of baked products. The type of sugar and their dissolution behavior can have a significant role during this process. Due to the ability of sugars to preferentially attract water over the gluten proteins, gluten development was hindered and hence, no dramatic increase in the thickness of biscuits was obtained (Handa et al., 2012; Kweon et al., 2009). In this study, the thickness of biscuits was significantly affected $(\mathrm{p}<0.05)$ by the types of sugar and dough relaxation time (Table 2 ). The thickness of biscuits prepared with dough relaxation for 15 min was in the order of dextrose $>$ S-IS $>$ IS $>$ honey $>$ sucrose. Significantly higher thickness in the biscuits prepared from biscuits with syrups compared to granular sucrose was also reported by Sai Manohar \& Haridas Rao(1997) and Zargaraan, Kamaliroosta, Yaghoubi, \& Mirmoghtadaie(2016). Curley \& Hoseney (1984) also reported that the replacement of sucrose with high fructose corn syrup (HFCS) had increased biscuit thickness compared to those prepared with sucrose only. The very low solubility of dextrose $(46 \mathrm{~g} / 100 \mathrm{~g}$ at $\left.20^{\circ} \mathrm{C}\right)$ compared to sucrose $\left(203 \mathrm{~g} / 100 \mathrm{~g}\right.$ at $\left.20^{\circ} \mathrm{C}\right)$ due to slow dissolution rate promotes hydration and development of gluten network (Handa et al., 2012; Nishibori \& Kawakishi, 1992; van der Sman \& Renzetti, 2018). Nishibori \& Kawakishi (1992) also reported that the vertical expansion of cookies prepared with glucose was higher than for those prepared with fructose and sucrose. Handa et al. (2012) also reported that the biscuits prepared with sugar of low solubility have higher thickness. When the biscuits were prepared with dough relaxation of $65 \mathrm{~min}$, the thickness was in the order of S-IS $>$ invert syrup $>$ sucrose $>$ honey $>$ dextrose. No statistical difference $(\mathrm{p}>0.05)$ was observed in the thickness of biscuits prepared with S-IS, IS, honey, and width of biscuits prepared with dextrose was reduced to the size similar to the initial state at the relaxation time of sucrose. Sai Manohar \& Haridas Rao (1997) however reported no significant difference in the thickness of biscuits prepared from sucrose and dextrose. This was possibly due to dough relaxation time of somewhere between 15 and 40 min. A significant decrease $(p<0.05)$ in the thickness of biscuits prepared using dextrose was observed with an increase in dough relaxation time. This waspossibly due to the solubilization of dextrose in dough and reduction of the wrinkling surface, which had the major contribution of the high stack height of dextrose biscuits. The dissolution of the crystal sugars reduces the wrinkling surface and balances the stack height (Kweon et al., 2009)

\section{Effect on spread ratio of biscuits}

Cookie spread refers to the ratio of diameter to height. Thus, the spread ratio is the combined parameter of sugar's effects on the diameter (sugar dissolution) and height (inhibiting gluten development) (Handa et al., 2012). In general, larger cookie diameter and higher spread are considered as the desired quality attributes (Yamamoto, 1997). The spread ratio of biscuits was significantly affected $(\mathrm{p}<0.05)$ by the type of sugar and dough relaxation time (Table 3 ). For dough relaxation time of $15 \mathrm{~min}$, biscuits prepared with aqueous sugars i.e. IS and honey had significantly higher $(p<0.05)$ spread ratio compared to those prepared with sucrose and S-IS. This was due to the more lateral expansion i.e. the width of biscuits prepared with liquid sugars compared to those with crystals. A higher spread ratio of biscuits prepared with different syrups in comparison to sucrose has also been reported elsewhere (Handa et al., 2012; Majzoobi et al., 2016). The least spread ratio of dextrose was however due to very high vertical expansion as discussed previously. When the relaxation time of dough was increased, no statistical difference $(p>0.05)$ was observed in the spread ratio of biscuits prepared with IS and honey. However, the spread ratio of biscuits prepared with partial or complete crystal sugars significantly increased. The dissolution of sugar crystals was the principal factor that increased the spread ratio of biscuits. An increase in the spread ratio of biscuits prepared with sucrose and S-IS was associated with the lateral expansion in width due to the dissolution of sucrose along with relaxation time.The dissolution of sugars increases the solvent volume in the dough and contributes to biscuit spreading (van der Sman \& Renzetti, 2018).

Table 2

Thickness of biscuits prepared with different types of sugars and dough relaxation time*

\begin{tabular}{|c|c|c|c|c|c|c|}
\hline \multirow{2}{*}{$\begin{array}{l}\text { Relaxation } \\
\text { time (min) }\end{array}$} & \multirow{2}{*}{$\begin{array}{l}\text { Initial thickness } \\
\qquad(\mathbf{m m})\end{array}$} & \multicolumn{5}{|c|}{ Final thickness (mm) } \\
\hline & & Sucrose & Dextrose & S-IS & IS & Honey \\
\hline 15 & $3.5^{\mathrm{e}}$ & $5.82 \pm 0.17^{\mathrm{Ad}}$ & $6.58 \pm 0.25^{\mathrm{Aa}}$ & $6.23 \pm 0.18^{\mathrm{Ab}}$ & $6.14 \pm 0.20^{\mathrm{Abc}}$ & $5.87 \pm 0.14^{\text {Acd }}$ \\
\hline 40 & $3.5^{\mathrm{d}}$ & $5.82 \pm 0.11^{\mathrm{Ab}}$ & $5.18 \pm 0.19^{\mathrm{Bc}}$ & $6.34 \pm 0.21 \mathrm{Aa}$ & $6.29 \pm 0.18^{\mathrm{Aa}}$ & $5.71 \pm 0.14^{\mathrm{Ab}}$ \\
\hline 65 & $3.5^{\mathrm{d}}$ & $5.79 \pm 0.12^{\mathrm{Ab}}$ & $4.66 \pm 0.15^{\mathrm{Cc}}$ & $6.44 \pm 0.17^{\mathrm{Aa}}$ & $6.42 \pm 0.13^{\mathrm{Aa}}$ & $5.59 \pm 0.13^{\mathrm{Ab}}$ \\
\hline
\end{tabular}

* All means and SD are calculated from 16 stacks (each with 5 pieces) collected in 2 blocks and 8 replicates per block. IS: invert syrup, S-IS: sucrose-invert syrup (1:1 in dry basis) mix. Different capital letters superscript in a column and small letters superscript in a row indicate significant difference among sample means at $\mathrm{p}<0.05$ such that $\mathrm{A}>\mathrm{B}>\mathrm{C}$ and $\mathrm{a}>\mathrm{b}>\mathrm{c}>\mathrm{d}>\mathrm{e}$. 
Table 3

Spread ratio of biscuits prepared with different types of sugars and dough relaxation time*

\begin{tabular}{ccccccc}
\hline $\begin{array}{c}\text { Relaxation } \\
\text { time (min) }\end{array}$ & $\begin{array}{c}\text { Initial spread } \\
\text { ratio }\end{array}$ & Sucrose & Dextrose & Spread ratio \\
\cline { 3 - 7 } & 10.57 & $6.84 \pm 0.18^{\mathrm{Bb}}$ & $5.99 \pm 0.28^{\mathrm{Cc}}$ & $6.55 \pm 0.24^{\mathrm{Bb}}$ & $7^{\mathrm{Aa}}$ & HS \\
\hline 15 & 10.57 & $7.30 \pm 0.14^{\mathrm{Aa}}$ & $7.22 \pm 0.23^{\mathrm{Ba}}$ & $7.19 \pm 0.19^{\mathrm{Aa}}$ & $7.15 \pm 0.19^{\mathrm{Aa}}$ & $7.39 \pm 0.15^{\mathrm{Aa}}$ \\
\hline 40 & 10.57 & $7.26 \pm 0.15^{\mathrm{Aab}}$ & $7.62 \pm 0.31^{\mathrm{Aa}}$ & $6.97 \pm 0.26^{\mathrm{Ab}}$ & $7.07 \pm 0.10^{\mathrm{Ab}}$ & $7.57 \pm 0.21^{\mathrm{Aa}}$ \\
\hline 65 & & &
\end{tabular}

* All means and SD are calculated from 16 stacks (each with 5 pieces) collected in 2 blocks and 8 replicates per block. IS: invert syrup, S-IS: sucrose-invert syrup (1:1 in dry basis) mix. Different capital letters superscript in a column and small letters superscript in a row indicate significant difference among sample means at $p<0.05$ such that $A>B>C$ and $a>b>c>d>e$.

The dissolution of sugars binds extra water molecules and retards the kinetics of growth of water vapor bubbles (Baldino et al., 2014; van der Sman \& Renzetti, 2018) but does not alter the kinetics of chemical leavening reactions (Chevallier et al., 2000). Kweon et al. (2009) reported no significant difference $(p>0.05)$ in the height of biscuits prepared with ultrafine and fine sucrose granules. This implies that the dissolution of crystal sugars had no significant effect on the height of biscuits, despite increased volume of dissolved sugars and total solvents in the dough with ultrafine sucrose granules as compared to fine sucrose granules.

In contrast to the dissolution of sucrose, the dissolution of dextrose along with the increase in relaxation time significantly increased $(p<0.05)$ the spread of biscuits by the collapse of the wrinkled surface. Hence, the high spread ratio of biscuits may not necessarily lead to desirable qualityattributes. Therefore, the factors affecting spread ratio i.e. width and thickness must be considered to interpret the values of spread ratio.

\section{Effect on expansion ratio of biscuits}

The expansion ratio of biscuits refers to the ratio of the final volume of biscuits to the initial volume of the dough piece. The expansion ratio of biscuits was significantly affected $(p<0.05)$ by the type of sugar, dough relaxation time, and their interaction (Table 4). This implies that the type of sugar influenced the effect of relaxation time of dough on the expansion ratio of biscuits and vice-versa. For dough relaxation time of $15 \mathrm{~min}$, the expansion ratio of biscuits prepared with aqueous sugars i.e. IS and honey was significantly higher $(\mathrm{p}<0.05)$ compared to others. As in the case of width, thickness and spread ratio, the expansion ratio of biscuits prepared with IS and honey were also unaffected with the increase in dough relaxation time.
An increase in the expansion ratio of biscuits prepared with sucrose and S-IS along with the increase in relaxation time was solely due to lateral expansion without any significant ( $>0.05)$ change in the vertical expansion (thickness). The lateral expansion was due to the dissolution of sucrose that increased the solvent volume of dough and resulted in the lateral expansion (van der Sman \& Renzetti, 2018). Majority of the studies on the effect of sugars and sugar replacement in the dimensions of biscuits have reported the inverse relation between the lateral and vertical expansion (Curley \& Hoseney, 1984; Kweon et al., 2009; Laguna et al., 2013; Thakur et al., 2009). However, in this study no significant $(p<0.05)$ change in the thickness of biscuits was observed when the width of biscuits was increased as the function of increasing dough relaxation time.

At the dough relaxation time of $15 \mathrm{~min}$, the expansion ratio of biscuits prepared with sucrose and dextrose were statistically similar $(\mathrm{p}>0.05)$. In contrast to the expansion ratio of sucrose, and the spread ratio of dextrose itself, the expansion ratio of biscuits prepared with dextrose significantly decreased $(p<0.05)$ with the increase in dough relaxation time. This decrease was associated witha decrease in both the width and thickness of biscuits. Nishibori \& Kawakishi (1992) reported that the expansion behavior of biscuits prepared with dextrose was because of its very low solubility in the dough. Because of the low solubility of dextrose, the majority of dextrose probably did not dissolve, which promoted the hydration and development of gluten. The decrease in width was associated with the snapback of sheeted and cut dough piece, possibly due to strengthening of gluten network during dough relaxation, while the decrease in thickness was possibly due to the dissolution of dextrose with the time that decreased the wrinkled surface, as discussed previously.

Table 4

Expansion ratio of biscuits prepared with different types of sugars and dough relaxation time*

\begin{tabular}{cccccc}
\hline \multirow{2}{*}{$\begin{array}{c}\text { Relaxation } \\
\text { time (min) }\end{array}$} & \multicolumn{5}{c}{ Expansion ratio } \\
\cline { 2 - 6 } & Sucrose & Dextrose & S-IS & IS & Honey \\
\hline 15 & $1.93 \pm 0.11^{\mathrm{Bc}}$ & $2.12 \pm 0.10^{\mathrm{Abc}}$ & $2.15 \pm 0.07^{\mathrm{Bb}}$ & $2.60 \pm 0.08^{\mathrm{Aa}}$ & $2.22 \pm 0.09^{\mathrm{Ab}}$ \\
\hline 40 & $2.20 \pm 0.13^{\mathrm{Ab}}$ & $1.51 \pm 0.09^{\mathrm{Bc}}$ & $2.74 \pm 0.17^{\mathrm{Aa}}$ & $2.66 \pm 0.13^{\mathrm{Aa}}$ & $2.13 \pm 0.12^{\mathrm{Ab}}$ \\
\hline 65 & $2.14 \pm 0.11^{\mathrm{Ab}}$ & $1.22 \pm 0.04^{\mathrm{Cc}}$ & $2.70 \pm 0.09^{\mathrm{Aa}}$ & $2.76 \pm 0.15^{\mathrm{Aa}}$ & $2.09 \pm 0.09^{\mathrm{Ab}}$ \\
\hline
\end{tabular}

* All means and SD are calculated from 16 stacks (each with 5 pieces) collected in 2 blocks and 8 replicates per block. IS: invert syrup, S-IS: sucrose-invert syrup (1:1in dry basis) mix. Different capital letters superscript in a column and small letters superscript in a row indicate significant difference among sample means at $p<0.05$ such that $A>B>C$ and $a>b>c>d>e$. 


\section{Conclusions}

The types of sugar and dough relaxation time, both had a significant effect $(p<0.05)$ on the shape of biscuits. The type of sugars significantly affected $(p<0.05)$ all shape characteristics, while the dough relaxation only affected those of crystal sugars (sucrose and dextrose). This study revealed that all physical parameters (viz. width, thickness, spread ratio, and expansion ratio) of biscuits with crystal sugars were significantly influenced $(\mathrm{p}<0.05)$ by type of sugars, while the dough relaxation only affected those of crystal sugars (sucrose and dextrose). With extended dough relaxation time, the width, spread ratio, and expansion ratio of biscuits with sucrose significantly increased $(p<0.05)$ while thickness remained unaffected. In contrast, the width, thickness, and expansion ratio of those with dextrose decreased while the spread ratio increased with an increase in dough relaxation time. At dough relaxation time of 15 min, the width of biscuits with liquid sugars, liquid-crystal mix, and crystals was in the decreasing order. When the dough relaxation time was increased, the width of biscuits with sucrose increased while that with dextrose decreased. On the other hand, the thickness of biscuits with dextrose was maximum at dough relaxation time of $15 \mathrm{~min}$ and decreased to be the minimum when 65 min while that with other sugars were unaffected by dough relaxation time. The highest spread ratio and the lowest expansion ratio of biscuits prepared with dextrose demonstrated that the spread ratio may not always be a good estimate of the dimensional properties of biscuits. Hence, both the spread ratio and expansion ratio needs consideration when discussing the shape of biscuits with different ingredients.

\section{Acknowledgment}

The research and publication of this article was supported by Nagarik College [Internal grant], Tribhuvan University, Nepal. The authors thank the board of Nagarik College, Mr. Chhabi Lal Kandel, and Mr. Madhab Pd. Tiwari for financial and material support.

\section{References}

Abboud, A. M., \& Hoseney, R. C. (1984). Differential scanning calorimetry of sugar cookies and cookie doughs. Cereal Chemistry, 61(1), 34-37.

Bagley, E. B., Christianson, D. D., \& Martindale, J. A. (1988). Uniaxial compression of a hard wheat flour dough: data analysis using the upper convected Maxwell model. Journal of Texture Studies, 19, 289305.

Baldino, N., Gabriele, D., Lupi, F. R., De'Cindio, B., \& Cicerelli, L. (2014). Modeling of baking behavior of semi-sweet short dough biscuits. Innovative Food Science and Emerging Technologies, 25, 40-52.

Chauhan, A., Saxena, D. C., \& Singh, S. (2016). Physical, textural, and sensory characteristics of wheat and amaranth flour blend cookies. Cogent Food \& Agriculture, 2(1), 1125773.

Chevallier, S., Colonna, P., \& Bule, A. (2000). Physicochemical behaviors of sugars, lipids, and gluten in short dough and biscuit. Journal of Agricultural and Food Chemistry, 48, 1322-1326.

Curley, L. P., \& Hoseney, R. C. (1984). Effects of corn sweetners on cookie quality. Cereal Chemistry, 61(4),
274-278.

Handa, C., Goomer, S., \& Siddhu, A. (2012). Physicochemical properties and sensory evaluation of fructoligosaccharide enriched cookies. Journal of Food Science and Technology, 49(2), 192-199.

Kweon, M., Slade, L., Levine, H., Martin, R., \& Souza, E. (2009). Exploration of sugar functionality in sugar-snap and wire-cut cookie baking: implications for potential sucrose replacement or reduction. Cereal Chemistry, 86(4), 425-433.

Laguna, L., Vallons, K. J. R., \& Jurgens, A. (2013). Understanding the effect of sugar and sugar replacement in short dough biscuits. Food and Bioprocess Technology, 6, 3143-3154.

Maache-Rezzoug, Z., Bouvier, J., Allaf, K., \& Patras, C. (1998). Effect of Principal Ingredients on Rheological Behaviour of Biscuit Dough and on Quality of Biscuits. Journal of Food Engineering, 35(1), 23-42.

Majzoobi, M., Mansouri, H., Mesbahi, G., Farahnaky, A., \& Golmakani, M. T. (2016). Effects of sucrose substitution with date syrup and date liquid sugar on the physicochemical properties of dough and biscuits. Journal of Agricultural Science and Technology, 18, 643-656.

Manley, D. (1998). Biscuit, Cookie and Cracker Manufacturing, Manual 4: Baking and cooling of biscuits. Woodhead Publishing Ltd.

Manley, D. (2011a). Setting the scene: A history and the position of biscuits. In Manley's Technology of Biscuits, Crackers and Cookies: Fourth Edition (pp. 1-9). Elsevier Ltd.

Manley, D. (2011b). Sugars and syrups as biscuit ingredients. In D. Manley (Ed.), Manley's technology of biscuits, crackers and cookies (4th ed., pp. 143-159). Woodhead Publishing Limited.

Manley, D., Pareyt, B., \& Delcour, J. A. (2011). Short dough biscuits. In D. Manley (Ed.), Manley's technology of biscuits, crackers and cookies (4th ed., pp. 331-346). Woodhead Publishing Limited.

Nishibori, S., \& Kawakishi, S. (1992). Effect of various sugars on the quality of baked cookies. Cereal Chemistry, 69(2), 160-163.

Pareyt, B., Talhaoui, F., Kerckhofs, G., Brijs, K., Goesaert, H., Wevers, M., \& Delcour, J. A. (2009). The role of sugar and fat in sugar-snap cookies: Structural and textural properties. Journal of Food Engineering, 90(3), 400-408.

Safari-ardi, M., \& Phan-thien, N. (1998). Stress relaxation and oscillatory tests to distinguish between doughs prepared from wheat flours of different varietal origin. Cereal Chemistry, 75(1), 80-84.

Sai Manohar, R., \& Haridas Rao, P. (1997). Effect of sugars on the rheological characteristics of biscuit dough and quality of biscuits. Journal of the Science of Food and Agriculture, 75(3), 383-390.

Sai Manohar, R., \& Haridas Rao, P. (1999). Effect of mixing method on the rheological characteristics of biscuit dough and the quality of biscuits. European Food Research and Technology, 210, 43-48.

Sai Manohar, R., \& Haridas Rao, P. (2002). Interrelationship between rheological characteristics of dough and quality of biscuits; use of elastic recovery of dough to predict biscuit quality. Food Research International, 35(9), 
807-813.

Thakur, B. R., Singh, R. K., Handa, A. K., \& Rao, M. a. (2009). Critical Reviews in Food Science and Nutrition Chemistry and uses of pectin - A review Chemistry and Uses of Pectin - A Review. Critical Reviews in Food Science and Nutrition, 37(1), 47-73.

van der Sman, R. G. M., \& Renzetti, S. (2018). Understanding functionality of sucrose in biscuits for reformulation purposes. Critical Reviews in Food Science and Nutrition, 59(14), 2225-2239.

Yamamoto, H. (1997). Rheological properties and baking qualities of selected soft wheats grown in the United States. Cereal Chemistry, 73(2), 215-221.

Zargaraan, A., Kamaliroosta, L., Yaghoubi, A. S., \& Mirmoghtadaie, L. (2016). Effect of substitution of sugar by high fructose corn syrup on the physicochemical properties of bakery and dairy products: a review. Nutrition and Food Sciences Research, 3(4), 3-11.

Zoulias, E. I., Piknis, S., \& Oreopoulou, V. (2000). Effect of sugar replacement by polyols and acesulfame-K on properties of low-fat cookies. Journal of the Science of Food and Agriculture, 80(14), 2049-2056. 